\title{
Las glorias del desarrollismo: el gobierno de Miguel Alemán
}

Felicitas López Portillo T.

CCYDEL-UNAM

\section{Análisis de la carrera pública de Miguel Alemán y de la política desarrollada durante el régimen.}

$\mathbf{N}$

o es fácil escribir acerca del periodo sexenal presidido por Miguel Alemán Valdés (1946-52) debido, entre otras causas, a la escasez debibliografia sobre el tema y a la satanización que su gobierno ha experimentado por parte de la retórica de izquierda, que lo califica de contrarrevolucionario, y de la que invoca la pureza virginal de los principios revolucionarios para acusarlo de traidor a los mismos. Con todo, es urgente volver los ojos-limpios de prejuicios ideológicos- a este régimen que sentó las bases del exitoso modelo de desarrollo basado en la sustitución de importaciones gracias al cual, durante casi cuatro décadas, la economía creció a una tasa anual de $6 \%$, aunque tal modelo se encuentra hoy en entredicho, por no decir que en calidad de cadáver, y se hallen lejanos los tiempos en que el optimismo y la confianza en la grandeza de México imperaban en la obra de gobierno.

\section{SEMBLANZA BIOGRÁFICA}

Miguel Alemán llegó a la presidencia de la república después de una carrera política signada porla buena suerte. Nació en 1905 en el poblado de Sayula, Veracruz, como hijo de un general carrancista que no dio su brazo a torcer ante los revolucionarios sonorenses de Agua Prieta, y que murió alzado en 1929 . A causa

\section{(1)}

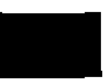


de la inconstante presencia del padre, la familia Alemán sufrió apuros económicos, pero, a pesar de ello, en 1928, don Miguel se recibió de abogado en la Universidad Nacional de México, después de haber cursado su preparatoria en la benemérita institución fundada por Gabino Barreda. Dos tentativas fallidas de convertirse en diputado no desalentaron su vocación política: entró al servicio público como abogado auxiliar de la Secretaría de Agricultura y Fomento y, enseguida, a la Junta Federal de Conciliación y Arbitraje. En adelante, su carrera fue en ascenso: en 1934 organizó la campaña presidencial de Lázaro Cárdenas en Veracruz y en 1935 fue nombrado magistrado del Tribunal Superior de Justicia y luego senador por su estado natal. En 1936, el asesinato del candidato a gobernador de Veracruz por el Partido Nacional Revolucionario (PNR), Manlio Fabio Altamirano en el café Tacuba de la ciudad de México, le abrió al licenciado Alemán las puertas de la gubernatura, de la que tomó posesión el 1 de diciembre de 1936.

Con motivo de la nacionalización petrolera, organizó un acto de apoyo delos gobernadores al presidente Cárdenas, lo que demuestra que el joven político sabía moverse en los vericuetos del poder. Simpático, astuto, de "rápida sonrisa", como lo calificaban los medios de comunicación de la época, Alemán representa a una nueva generación que no participó en la lucha armada, pero que sufrió sus consecuencias, por lo que se aprestó a tomar el timón con un designio específi$\mathrm{CO}$ : pacificar por completo al país y buscar su desarrollo económico, al que veía como condición indispensable para el mejoramiento integral del pueblo mexicano.

En su autobiografia Semblanzas y testimonios, escribe el ex presidente que para su carrera política resultaron de gran ayuda la experiencia y los consejos del general Cándido Aguilar y el licenciado Luis I. Rodríguez; este último era el secretario particular del presidente Lázaro Cárdenas. Dueño de un envidiable pragmatismo, el licenciado Alemán, antes de dedicarse de lleno a la política, quiso garantizar la seguridad económica para su familia. Después de unos fallidos negocios de exportación de frutas tropicales a Europa, dio en el blanco con el negocio de los bienes raíces. Junto con su entrañable amigo Gabriel Ramos Millán, construyó el fraccionamiento México en Cuernavaca; posteriormente fraccionaron la hacienda de los Morales, de donde surgiría la zona residencial de Lomas de Chapultepec. Años después fue el iniciador de Ciudad Satélite, proyecto urbano de inspiración estadunidense. La nueva camada de políticos revolucionarios conjugaba, sin contradicción alguna, la carrera del servicio público junto al mejoramiento de su situación económica, hecho que por lo demás no es novedad en nuestro país.

Durante su gobierno en Veracruz (que hasta donde sé no ha sido estudiado todavía), el licenciado Alemán acabó con las querellas dentro del sector campesino de la entidad; concertó la paz con la Iglesia y se esmeró en construir la indispensable infraestructura para el desarrollo estatal. En 1939 el general Manuel Ávila Camacho lo nombró coordinador general de su campaña electoral; en 1940 fue nombrado secretario de Gobernación y desde este puesto decisivo estableció las alianzas y mediaciones en el plano nacional que lo hicieron aparecer como un deseable candidato a la presidencia. En junio de 1945 la Central de Trabajadores de México (CTM) fue la primera central que se manifestó en favor de su postulación; en enero de 1946 
el recién nacido Partido Revolucionario Institucional (PRI) lo declaró oficialmente su candidato. Era el primer civil que aspiraba a la presidencia después de la retahíla de generales que nos deparó la revolución armada de 1910. Los caudillos revolucionarios estaban fuera de combate por su avanzada edad y por la creciente profesionalización del ejército favorecida por la guerra, junto a la creciente consolidación del presidencialismo.

La candidatura de un abogado egresado de la máxima casa de estudios, que inauguraba así un predominio en la formación de la clase política del país, hoy en entredicho, obedecía a concretas circunstancias históricas. Si Âvila Camacho había sido un candidato de transición entre un gobierno como el cardenista, quellevó hasta límites insospechados las demandas campesinas y obreras establecidas en la Constitución -acompañadas de un discurso de lucha de clases que asustó a la burguesía, a las clases medias mexicanas y a Estados Unidos-, Alemán llegaba recién inaugurada la posguerra cuando, gracias a la política de concordia y unidad nacional del avilacamachismo, habían quedado limadas las asperezas entre los diversos sectores sociales enfrentados en los años precedentes.

El recambio correspondía ahora a una nueva generación, de origen predominantemente urbano, clasemediera, con educación universitaria, lanzada a la fáustica tarea de modernizar el país con un proyecto económico que privilegiaba el apoyo al capital y la iniciativa privados, y hacía énfasis en el papel rector del Estado con objeto de lograrun desarrollo equilibrado que dejara atrás la miseria y la ignorancia, males seculares de nuestro pueblo. Todo sazonado con una envidiable estabilidad política, condición in- dispensable para el crecimiento económico y prenda mayor del sistema político surgido de la revolución de 1910. Como se lee en el programa de gobierno del licenciado Alemán:

El problema primordial de nuestro pueblo sigue siendo la conquista de la riqueza para el bienestar y el honesto goce de la vida; por eso estamos decididos a combatir la pobreza y abolir la miseria, elevandolas condiciones de vida de la población entera. Las nuevas necesidades que el pueblo debe satisfacer para su mejoramiento aumentarán su capacidad de consumo y esta circunstancia vitalizará el desenvolvimiento económico, agrícola e industrial que nos proponemos.'

\section{LA TRANSICION AVILACAMACHISTA}

El gobierno del general Manuel Ávila Camacho allanó el camino para el modelo abiertamente capitalista del siguiente régimen. Durante su periodo, la economía se encaminó hacia la sustitución de importaciones favorecida por la guerra y se aprovecharon las oportunidades de exportación abiertas por la misma, con lo que la industria mexicana tuvo acceso a nuevos mercados que luego se revelaron efimeros. Los salarios reales no crecieron al ritmo de la inflación e incluso se les puso freno al prohibirse las huelgas por razones de seguridad nacional; en compensación por lo anterior, se estableció el seguro social. Se reforzó el papel arbitral del Estado,y se retiró al sector militar del Partido de la Revolución Mexicana (PRM). Igualmente se eliminó la orientación socialista del artículo $3^{\circ}$ a fin de limar asperezas con importantes sectores p. 18.

${ }^{1}$ Miguel Alemán, Programa de gobiemo, 1945,

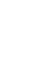

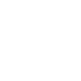

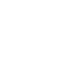

$=$ 
sociales, se disminuyó el reparto de tierras por el mismo motivo y se aumentó la dotación de certificados de inafectabilidad. En diciembre de 1941 se expidió un decreto de parcelación de los ejidos pero no se llegó a titularlos, lo que los convertiría en propiedad privada. Con motivo de la emergencia bélica se prestó apoyo a las democracias con materias primas, productos manufacturados, precios castigados y braceros, situación que ahondó los lazos comerciales de nuestro país con Estados Unidos en detrimento de nuestra ya de por sí menguada autonomía relativa. Con todo, destaquemos que no se cedió territorio para el establecimiento de bases militares y que se participó tardíamente en la guerra.

Las circunstancias provocadas por el conflicto armado hicieron posible en nuestro país la formación de grandes y rápidas fortunas, ligadas sobre todo a la especulación con bienes de consumo, que eran enviados al exterior, y a la inclusión de la industria mexicana en áreas antes desconocidas como la exportación de textiles a los países centro y sudamericanos. Bajo el manto de la unidad nacional, en abril de 1945 se firmó el pacto obrero industrial entre la CTM, la CNIT y la CONCAMIN, donde se reconocía la interdependencia económica que se veía venir al término de la contienda y la necesidad de una concertación entre capital y trabajo que posibilitara el avance industrial y elevara el nivel de vida popular. Se admitía que el capital extranjero era necesario, siempre y cuando se asociara al esfuerzo del desarrollo mexicano y no expoliara recursos naturales y mano de obra. En 1941 se creó la Secretaría del Trabajo y Previsión Social, en lugar del Departamento Autónomo del Trabajo, con lo que se afianzó el control estatal sobre el movimiento obrero.

Luis Medina, connotado especialista del periodo, escribe que durante el gobierno de Manuel Ávila Camacho em-

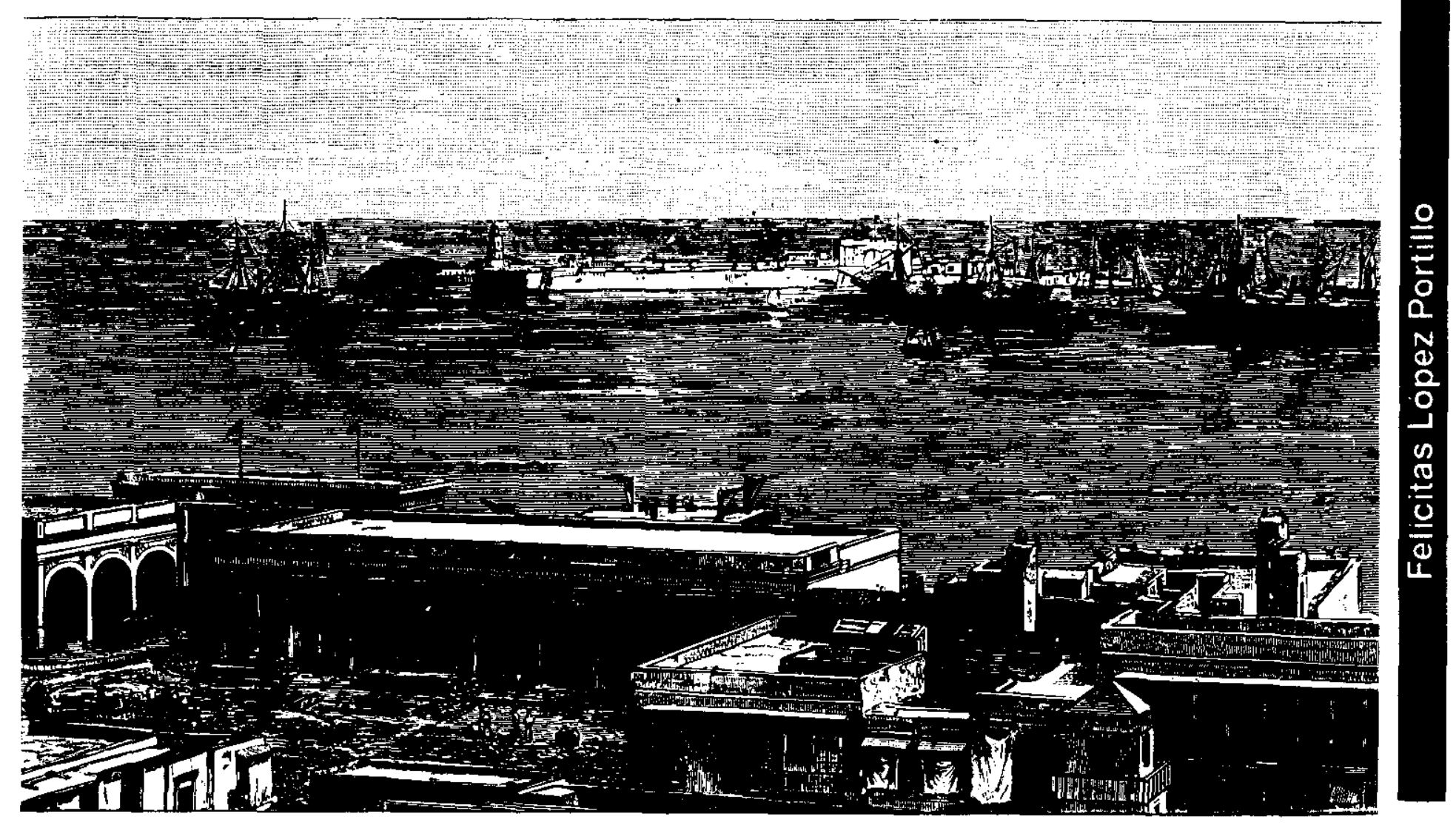


pezó a perfilarse un importante cambio ideológico, que fue "el de la idea del crecimiento económico como fin y justificación de la revolución mexicana", claro antecedente del gobierno que le sucedió.

\section{EL HERALDO DE LA INDUSTRIALIZACIÓN}

Vicente Lombardo Toledano, el prominente líder de la CTM durante el cardenismo, fue de los primeros en señalar los rumbos industrialistas que debía tomar la revolución. En septiembre de 1944, en ocasión de la Asamblea del Sector Revolucionario de México, compuesta por los tres sectores del Partido de la Revolución Mexicana: CTM, CNC (Confederación Nacional Campesina), y CNOP (Confederación Nacional de Organizaciones Populares), celebrada para analizar los problemas fundamentales del país de cara a la posguerra, el dirigente aclaró que su intención no era enlistarse en la contienda por la sucesión presidencial, sino expresar lo que consideraba debía ser el programa "de la nación mexicana en marcha".

En su conferencia, que se conoce por su versión taquigráfica, Lombardo señaló lo que consideraba comolos tres grandes problemas de México a través de su historia: la parquedad de los recursos naturales y su desigual distribución por el territorio nacional, la supervivencia del régimen feudal de la colonia y la intervención del imperialismo extranjero, obstáculos que explicaban a su vez la persecución de los mismos objetivos en las grandes revoluciones que ha protagonizado el pueblo mexicano (la de 1810,

${ }^{2}$ Luis Medina, Del cardenismo, 1978, p. 283. la de reforma y la de 1910). En sus palabras: "queremos serun pueblo que tenga posibilidades de cultura, posibilidades de trabajo, posibilidades de vivir de un modo civilizado; y queremos que México sea no un país semicolonial, sino una nación soberana, emancipada de veras, tanto desde el punto de vista político, como desde el punto de vista material". ${ }^{3}$

En lo referente a la falta de recursos naturales, Lombardo adelantaba uno de los argumentos preferidos por el alemanismo: esuna "mentira piadosa" lo del cuerno de la abundancia; México posee un suelo pobre, surcado por una sinuosa orografia, carece de agua (la excepción son las cuencas de los grandes ríos, por lo demás escasos); 79\% de la tierra es de cultivo temporalero, lo que se refleja en el hecho de que ocupemos el lugar 58 a nivel mundial en lo que respecta al rendimiento de maíz por hectárea, a pesar de que $66 \%$ de la población económicamente activa está ocupado en el campo. De lo anterior se colige que nuestro país jamás será una gran nación agrícola, pues carece de los recursos naturales para ello. En cuanto al segundo punto, aseguraba que seguíamos siendo un país exportador de minerales, como durante la época colonial, aunque por otra parte se había roto una de las supervivencias de aquélla, la existencia de una estructura territorial dominada por el latifundio, gracias a la reforma agraria de la revolución de 1910. No dejó de señalar que durante el porfiriato $1 \%$ de la población rural poseía $97 \%$ de la superficie censada del país; ${ }^{4}$ durante la dictadura, a pesar de los pregonados éxitos materiales del régimen, continuamos siendo un país

\footnotetext{
${ }^{3}$ Vicente Lombardo Toledano, Selección de obras, 1972, p. 69.

4 Ibid., p. 61.
}

\section{6}

5 
importador de bienes suntuarios y exportador de minerales, como en la colonia. La única industria que merecía tal nombre era la textil, y el capital extranjero controlaba los renglones más dinámicos de la economía. Lombardo Toledano negaba enfáticamente que la revolución hubiera fracasado en materia agraria; aseguraba que la productividad del ejido era la adecuada y que el principal problema del campo era el crédito, que estaba acaparado en un $90 \%$ por los comerciantes agiotistas y prestamistas. Los gobiernos emanados de la revolución se habían preocupado por tecnificar la agricultura, pero a pesar de ello "todavía pesa sobre México la pobreza original de nuestro país, su falta de recursos naturales para la agricultura".

La salida a esta situación había sido el impulso a la industrialización, que sin embargo, a pesar de todos los esfuerzos, todavía no daba los frutos esperados: $98 \%$ de las exportaciones mexicanas estaba compuesto de materias primas o semielaboradas, y $86 \%$ de nuestras importaciones era artículos manufacturados o semielaborados. Sólo $10 \%$ de la industria nacional producía insumos básicos: electricidad, siderurgia, productos químicos. A pesar de tan desalentador cuadro, Lombardo argumentaba que estábamos mejor que cuando el porfiriato, ya que las reformas revolucionarias habían elevado el nivel de vida popular, base firme para emprender con mejores bases la industrialización. Veía el destino del país con optimismo, pues si bien era cierto que para $194020 \%$ de la riqueza nacional estaba en manos extranjeras (30\% durante el porfiriato), el petróleo era nuestro, así como una parte creciente de la industria eléctrica, y la totalidad de la tierra.

s Ibid., p. 65.
El orador concluía que para romper los nudos gordianos de nuestros ancestrales problemas era necesario estudiar nuestra historia a fin de conocer la causa de los mismos y solucionarlos de la mejor manera; que lo que se imponía en la actualidad era abocarse a aumentar la riqueza nacional. La meta debía ser: "Mayor prosperidad para el porvenir. Sin ella, nada es posible pensar del progreso colectivo de la nación."6 Para lograr tal objetivo era necesario darleuna atención preferencial a la agricultura, modernizándola y capitalizándola; los esfuerzos debían encaminarse hacia cultivos de alto rendimiento y precio y a estimular la agricultura tropical, que tiene grandes posibilidades de exportación. Junto al abandono de la agricultura tradicional, de subsistencia, debía darse la batalla por la industrialización:

Industrializar a México, revolucionar a nuestro país mediante la industrialización, hacer de la producción una unidad indivisible, de acuerdo con un plan previsor, lleno de estímulo, es la única solución que puede ofrecerse a un país que no sólo quiere vivir mejor -vieja aspiración secular- sino que va a ser objeto o puede serlo en la posguerra, de la intromisión de poderosas fuerzas económicas del extranjero.?

El líder obrero opinaba que la mejor arma de nuestro país para enfrentarse al imperialismo, que surgiría de la guerra "más agigantado que nunca", era la independencia económica. La tarea de la emancipación económica de México era "una de las mejores, de las más grandes, de las más altas tareas históricas que un pueblo consciente de sú destino puede

\footnotetext{
${ }^{6}$ Ibid., p. 71.

${ }^{7}$ Ibid., p. 72.
} 
proponerse: nuestra emancipación total, nuestro progreso incesante, inmediato". ${ }^{8}$ En esta obra, el concurso de todos los mexicanos era necesario. Todos, sin excepción, debían cooperar: "campesinos, obreros, artesanos, pequeños industriales, rancheros, pequeños propietarios rurales, comerciantes en pequeño, grandes comerciantes no agiotistas, no especuladores, grandes industriales y banqueros". ${ }^{9}$ Hacía especial consideración a las clases medias, las que debían recibir estímulo y protección estatales, e incluía en las mismas a los profesionistas liberales y a los miembros de las fuerzas armadas. La única condición exigida para colaborar en esta tarea de superación era el patriotismo y la honestidad, y el deseo de mejorar las condiciones de vida de los mexicanos.

Lombardo Toledano dividió el programa propuesto en dos partes: la primera, concerniente a la política exterior de México, abarca los siguientes principios, que no debían abandonarse por ningún motivo: la amistad y solidaridad con todos los pueblos; la defensa del régimen democrático como sistema universal de gobierno; la condenación a toda política de agresión, y la participación de México en un sistema de seguridad colectiva que garantizara el respeto a la soberanía de las naciones, el apoyo a la independencia política y económica de todos los países coloniales, semicoloniales y dependientes, la cooperación fraternal con América Latina y el decidido respaldo a la política del buen vecino, dada la necesidad de convivir amigablemente con Estados Unidos, país que albergaba en su seno sectores sociales simpatizantes con las luchas de nues-

\footnotetext{
${ }^{8}$ lbid., p. 73.

${ }^{9}$ Ibid., p. 71.
}

tro pueblo, y el cumplimiento de los principios y objetivos contenidos en la Carta del Atlántico y en los acuerdos de la conferencia de Teherán. ${ }^{10}$

En cuanto al segundo punto, Lombardo resumía los ideales históricos que conforman el programa de las tres grandes revoluciones nacionales acaecidas en México: "1) La plena autonomía económica y política de la nación. 2) El desarrollo económico del país. 3) La elevación de las condiciones materiales y culturales en que viven las grandes masas del pueblo. 4) El respeto fiel a la voluntad popular para el eficaz funcionamiento de las instituciones democráticas." ${ }^{11}$ Para el cumplimiento de tales condiciones se requería regular la inversión extranjera para impedirle el control de ramas fundamentales de la economía y el desplazamiento del capital nacional; debía aquélla encaminarse primordialmente hacia actividades productivas que nuestra economía demandaba para su buen funcionamiento, reinvertir sus utilidades y respetar la legislación referente a los derechos de los trabajadores. Sobre todo, debía cuidarse sobremanera que los precios de las materias primas de exportación fuesen justos, equiparables a los precios de los bienes de capital y manufacturas de importación. El conferencista alertaba sobre el hecho de que el mayor esfuerzo debía venir de nosotros mismos, del uso racional y adecuado que se hiciera de los escasos recursos de capital y naturales disponibles.

Había que echar mano de la técnica -patrimonio de toda la humanidad- a efecto de ampliar la industria eléctrica, siderúrgica y química, así como la de bienes de capital y de consumo, y propiciar la modernización de los centros
${ }^{10}$ Ibid., p. 78.
${ }^{11}$ Ibid. 
industriales ya establecidos. En cuanto a los transportes, recomendaba la rehabilitación de los ferrocarriles, la ampliación de la red de carreteras, la formación de una marina y una aviación mercantes. El escaso crédito debía orientarse prioritariamente hacia las actividades productivas, no hacia las especulativas, como sucedía generalmente; asimismo encarecía la creación de un sistema de crédito popularbarato para los artesanos, al igual que para los pequeños y medianos industriales.

Lombardo insistía en que el desarrollo económico no era un fin en sí mismo, sino que éste "debe tener como objetivo la elevación de las condiciones materiales y culturales de las grandes masas del pueblo". ${ }^{12}$ Para lograr los objetivos deseados, la función interventora del Estado era esencial: precisaba controlar los precios y racionalizar la distribución de productos básicos, incrementar el poder adquisitivo de los trabajadores mediante el aumento de los salarios reales, ampliar el seguro social y mejorar los servicios sanitarios y de asistencia social. Sugería perfeccionar la legislación protectora del trabajadory la expedición de una ley federal de protección a la infancia, a la par que señalaba la necesidad de incorporar a la población indígena, la más marginada del país, a la vida nacional.

La educación debía recibir una especial atención, buscando extenderla al máximo, con atención preferente a las masas iletradas. Lombardo alertaba sobre el peligro de que la juventud, descuidada por los gobiernos revolucionarios, cayera en las redes demagógicas del Partido Acción Nacional (PAN) y de la Unión Nacional Sinarquista (UNS); para evitarlo debía enseñárseles a los jóvenes lo que fue el porfirismo y contrastarlo con los avances sociales de la revolución. Aconsejaba que a nivel medio se diera preparación en artes y oficios, para que los alumnos egresaran con una carrera técnica que les ayudara a enfrentarse a la vida con una mejor preparación. Manifestaba que la energía juvenil podía aprovecharse en la reforestación, el arreglo de archivos históricos, la construcción y organización de centros deportivos, entre algunas otras actividades.

Refutaba el líder obrero las voces interesadas que señalaban que la coyuntura mundial era propicia para encaminar a México hacia el socialismo. Aunque hacía profesión de fe marxista, reconocía que todo mundo, inclusive los liberales, coincidían: "en México, para la posguerra, no tratamos de conseguir la abolición del régimen de propiedad; que no pretendemos instaurar el socialismo en esta tierra, porque ni las condiciones históricas domésticas, ni las circunstancias internacionales, hacen propicia tarea tan trascendental". ${ }^{13}$ Terminaba su vigoroso alegato en pro de un nuevo rumbo para México: "Camaradas del sector revolucionario de México: iA construir con nuevo vigor la etapa de la revolución industrial de México, una gran nación digna de nuestra raza, de nuestro pasado y de nuestro porvenir!"14

La industrialización, proyecto medular del gobierno alemanista, venía siendo apoyado desde tiempo atrás, concretamente desde 1938 cuando Lázaro Cárdenas llegaba al clímax en su política nacionalista y reafirmadora de la soberanía estatal y deseaba no tanto ensanchar las conquistas revolucionarias cuanto consolidar las ya logradas. Por
${ }^{12}$ Ibid., p. 84.
${ }^{13}$ Ibid., p. 69.
${ }^{14}$ Ibid., p. 93. 


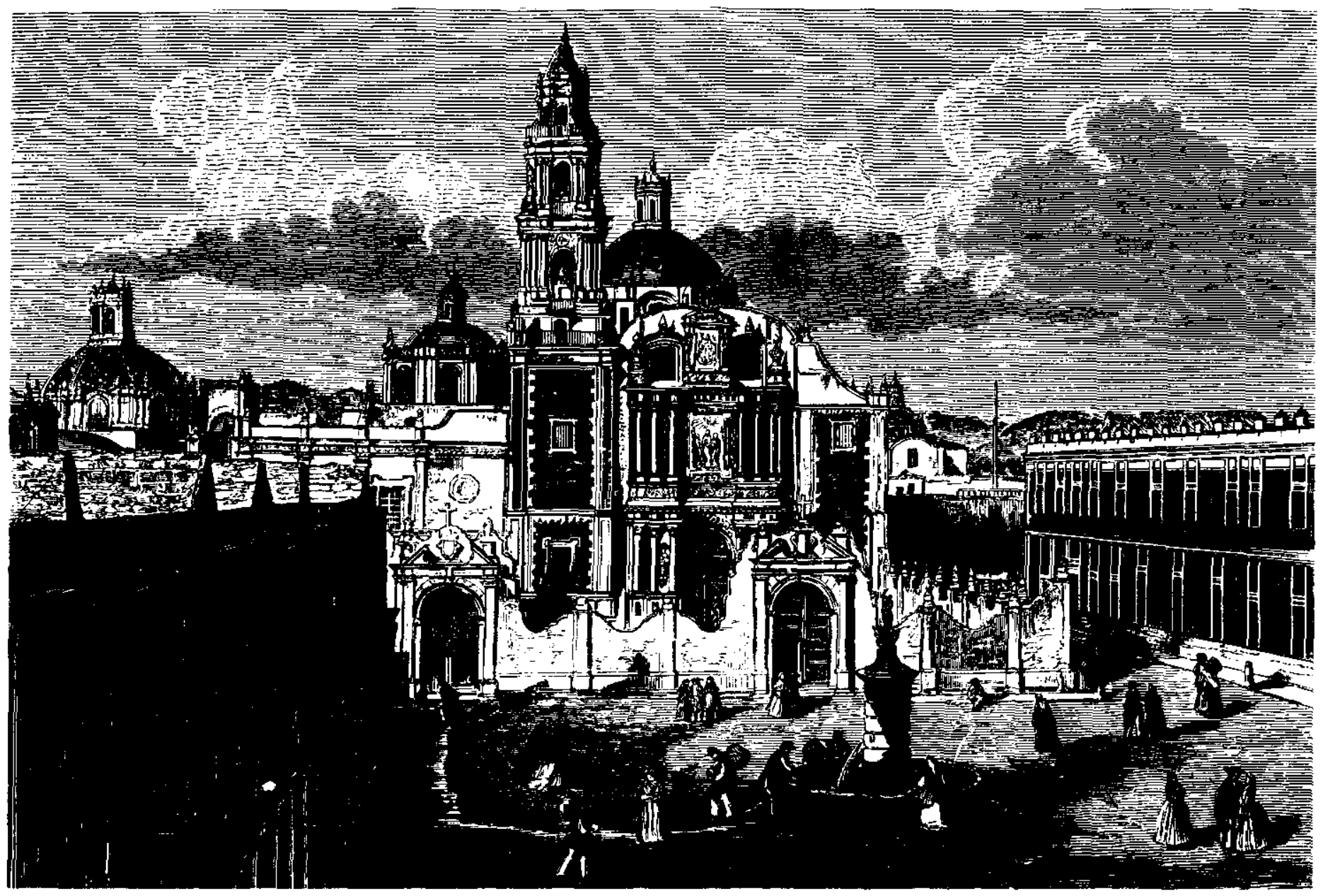

ejemplo, en diciembre de 1939 expidió un decreto que eximía de impuestos durante cinco años a empresas industriales nuevas. También se empeñó en apoyar a la pequeña y mediana burguesías, que se orientaban sobre todo a satisfacer el exiguo mercado interno y entraban en contradicción con la gran burguesía. El gasto público durante el periodo cardenista tuvo un carácter inflacionario, lo que sirvió para crear una infraestructura que a su vez estimuló a la industria manufacturera. Ésta era, desde 1937, la principal actividad productiva del país por su posición dentro de la estructura del ingreso nacional.

\section{El GOBIERNO DE MIGUEL ALEMÁN}

Miguel Alemán ascendió a la presidencia acompañado de un equipo de hombres con un promedio de edad de 42.5 años y con el calificativo de técnicos, al que no. consideraban peyorativo sino una garantía de que los problemas se encararían en forma racional y eficiente, aplicando criterios sobre todo económicos y no políticos en la solución de los mismos. Bajo estas premisas, durante la campaña electoral se realizaron una serie de mesas redondas que consistían en reuniones del candidato presidencial y sus asesores con representantes de las principales fuerzas productoras de determinada industria o región económica, para analizar un problema dado, por ejemplo el de la modernización de la industria textil, y recibir proposiciones para solucionarlo de parte de todos los sectores interesados.

La preocupación total del régimen será económica y a ella deberá supeditarse todo lo demás. Luis Medina escribe que "en términos generales, Alemán deseaba construir una economía moderna, basada en la iniciativa y en la inversión privada y en una actividad rectora del 
Estado que, a través del control de las industrias básicas, fomentara la actividad económica general". 15

Ramón Beteta, el influyente personaje del gobierno alemanista que fungiera como secretario de Hacienda del mismo, escribió en su libro Entrevistas y pláticas que se pensó, por parte del nuevo equipo gobernante, en la necesidad de seguir una política económica moderada, de bajo perfil, a causa de las dificultades que se encaraban en la posguerra pero que durante la campaña presidencial del candidato oficial, en todas partes del país se le pedía crecimiento, por lo que se decidieron a seguir la vía del desarrollo económico, aun a costa del riesgo inflacionario.

Sea como fuere, el hecho es que desde que la CTM postuló a Miguel Alemán como su candidato presidencial en junio de 1945 , se dieron a conocer los lineamientos en que se apoyaría para su actuación el futuro gobierno -si contaba con el favor del voto popular, of course. La central obrera afirmó que su decisión se sustentaba en el hecho de que su candidato representaba, como ningún otro, los intereses clasistas de los trabajadores; su origen familiar, hijo de un general revolucionario, asílocertificaba, lo mismo que su nacionalismo, su defensa intransigente de los ideales agrarios y obreros de la revolución, su antiimperialismo y su honestidad, cualidades que compartía con el general Lázaro Cárdenas. ${ }^{16}$ En esta ocasión la organización obrera hizo votos porque en el próximo gobierno se abriera una "nueva etapa de auténtico progreso, de fraternidad, de justicia y de

\footnotetext{
${ }^{15}$ Luis Medina, Civilismo y modernización del autoritarismo, 1982, p. 151.

${ }^{16} \mathrm{CTM}$, Por la grandeza de México con Miguel Alemán, 1945, p. 13.
}

paz" en bien de los mexicanos y de sus instituciones. ${ }^{17}$

Por su parte, el elegido agradeció la designación y señaló que el logro de las libertades humanas y la justicia económica habían sido los postulados esenciales de la revolución, mismos principios debatidos en la conflagración mundial, por lo que, concluía, la revolución mexicana se había adelantado en mostrar al mundo el camino a seguir en pos de la democracia y la justicia social.

En esta oportunidad Miguel Alemán dio a conocer la preocupación toral de su gobierno, que no sería otra que la resolución de los graves problemas que agobiaban a nuestro pueblo. Categórico, exclamó que "el país entero reclama la industrialización de México", ${ }^{18}$ frase que sintetiza su futura política económica. Para reforzar su argumentación sobre la necesidad de lograr la independencia económica del país, señaló que la revolución había hecho posible que se gozara en México de un clima de libertades ciudadanas, pero que debíamos "aprestarnos con fe y con vigor a la resolución delos problemas económicos sin lo cual, las otras libertades de que gozamos, podrían parecer irrisorias". ${ }^{19}$ Apuntó asimismo que la redención económica no podía venir más que de nosotros mismos, de nuestro trabajo y esfuerzo, aunque no desdeñó la utilidad de la ayuda externa.

En cuanto al sector privado -enajenado en su mayoría por las políticas de los gobiemos revolucionarios, sobre todo del cardenista- se tendió un puente hacia la reconciliación con él cuando

\footnotetext{
${ }^{17}$ Ibid., p. 17.

${ }^{18}$ Ibid., p. 27.

${ }^{19}$ Ibid., p. 25.
} 
Alemán dijo que la iniciativa privada "debe tener la mayor libertad y contar con la ayuda del Estado para su desarrollo, cuando se realice con positivo beneficio del interés colectivo", ${ }^{20}$ lo que indica la pauta del futuro comportamiento oficial a este respecto, que privilegió la capitalización y creación de riqueza en detrimento del esfuerzo por un mejor reparto. $\mathrm{El}$ postulante señaló que en su gobierno se garantizaría "la libertad de los hombres de empresa para abrir centros de producción y multiplicar la industrialización del país, seguros de que sus inversiones estarán a salvo de las contingencias de la injusticia" ${ }^{21}$ Reconoció asimismo que los trabajadores tenían asegurados derechos inalienables y que contarian con el favor oficial

${ }^{20}$ Ibid., p. 26.

${ }^{21}$ Ibid., p. 27. por ser la parte más débil de la relación capital-trabajo; Alemán añadió que se buscaría un saludable equilibrio entre ambos factores de la producción a efecto de superar los problemas que existían entre ellos, reconociendo que el crecimiento económico debía tener como valor moral el de ser justo y equitativo.

El país estaba en calma; el PNR, un partido de partidos, se convirtió en partido de sectores con el PRMy, en enero de 1946 , su nieto era nombrado PRI, para adecuarlo a la realidad. El partido de la revolución institucionalizada fue bautizado con óleos democráticos, ya que se especificaba que las elecciones para postulargobernadores, senadores, diputadoslocales y federales y jueces-cuando estos últimos lo fueran por elección popular- se harían por sufragio universal y directo, mientras que el candidato presidencial se designaría en una con-

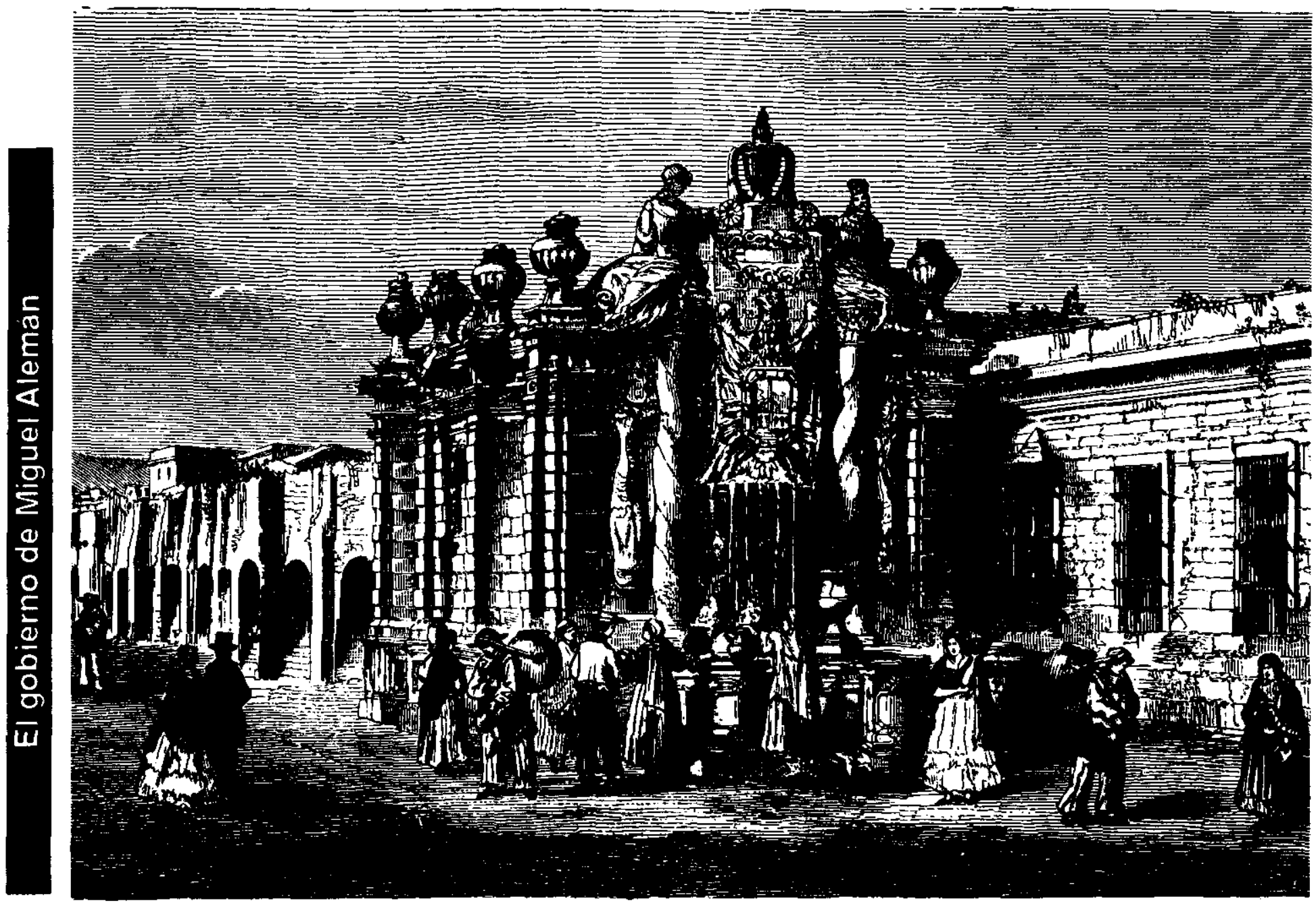


vención nacional, aunque se acordaba que antes tendría que haber consenso previo de las direcciones de los sectores del partido sobre las candidaturas. Junto con esta democratización, que como práctica fue abandonada posteriormente, ya que el proyecto modernizador en lo económico exigía el control político, se favoreció la disciplina partidaria y una mayor centralización en torno al gobierno federal, en lo que Luis Medina calificó como la "modernización del autoritarismo".

En la década de los 40 se afirmaron los rasgos característicos del sistema político mexicano que dieron lugar a la edad de oro del "desarrollo estabilizador": presidencialismo civil, partido oficial, fomento y control institucional de las organizaciones populares, amplia intervención del Estado en la promoción dela economía, la cultura y la organización de la sociedad. ${ }^{22}$ Con el alemanismo se dio la puntilla a la izquierda oficial, se controló el movimiento obrero mediante el charrismo y se otorgaron concesiones al liderazgo sectorial del PRI como premio a la domesticación de obreros y campesinos. Igualmente se consolidó la preeminencia del ejecutivo en el sistema político mexicano, la cual había vivido su primer momento estelar cuando Calles fue expulsado por don Lázaro.

Durante el sexenio alemanista, a pesar de que la iniciativa privada contó con todas las facilidades para conducir mejor sus negocios -exenciones de impuestos a industrias nuevas y necesarias, parques industriales equipados, protección arancelaria, insumos baratos, modernización de la infra estructura, control salarial, mayor volumen de crédito y subp. 43.

${ }^{22}$ Francisco J. Paoli, Estado y sociedad, 1985, sidios al consumo popular- no dejó de quejarse amargamente de lo que consideraba parcialidad oficial hacia los trabajadores. Consideró injusta e inadecuada la Ley Federal del Trabajo, se opuso a los contratos colectivos y a la determinación del salario mínimo, así como a la que consideraba nociva injerencia política en los sindicatos, que únicamente debían abocarse para defender los derechos desus agremiados. Los patrones denunciaron que los obreros no sólo tenían derechos, sino también obligaciones, entre las que se contaba trabajar.

Desde el poder se quería que la burguesía fuera dinámica, emprendedora, nacionalista, competitiva y con sentido social, que olvidara las ganancias fáciles que algunos de sus integrantes tuvieron durante la guerra -a través de la especulación con productos básicos y de la exportación-y que se dedicara a trabajar por una producción abundante, barata y de calidad, aunque se reconocía que por un tiempo tendría que haber sacrificios de los consumidores, ya quela industria mexicana de bienes de consumo no tenía posibilidades de competir ventajosamente con la estadunidense, pues sus costos, que deberían abatirse a través de la innovación tecnológica y la adopción de modernos métodos de administración de personal, eran más altos en aquel momento.

En lo que respecta a los trabajadores, los obreros y los campesinos, se encontraban incorporados al Estado en el pacto corporativo orquestado en la década de los 30 , que les otorgaba beneficios y prebendas, pero que coartaba su libertad de acción en desmedro de su madurez como clase. Como se señaló anteriormente, la CTM fue el primer sector del PRM que lanzó a Alemán como su candidato presidencial; el líder de aquel organismo laboral, Vicente Lombardo Toledano, ca- 
lificó al postulado como "cachorro de la revolución" y legítimo heredero de ella. Mas pronto se vio que los designios del nuevo gobierno no eran contemporizar con la retórica de izquierda. En 1947 se expulsó a Lombardo de la CTM y se cambió el lema de la central obrera, que pasó del agresivo "Por una sociedad sin clases", al inocuo "Por la emancipación de México". El esfuerzo industrializador recayó en las espaldas de los trabajadores, ya que la mayor productividad no fue acompañada de aumentos al salario, mientras sectores importantes de la burguesía lucraban con un mercado cautivo que, a pesar de todo, se ampliaba y diversificaba.

El programa alemanista se quería alejado de la retórica de la lucha de clases (aunque este principio no se eliminó del nuevo partido). Se pretendía "un gobierno de decisión y de trabajo, integrado por un gabinete ajeno a la política; intolerancia a los extremismos y exaltación de la mexicanidad como doctrina única; castigos implacables para los funcionarios deshonestos y respeto para todos los ciudadanos". ${ }^{23}$

Por su parte, los sectores medios sufrieron los rigores de la inflación y la carestía originadas durante el periodo de la guerra y los años posteriores a ella, pero esperaban mejorar su situación con el impulso a la economía prometido por el nuevo gobierno. Desde 1943, con la creación dela CNOP cuentan con un medio para tener acceso a la carrera política, la cual se convertirá en la mejor de las profesiones gracias a las oportunidades de enriquecimiento que caracterizan a los nuevos tiempos.

A este respecto, destacan las voces críticas de don Daniel Cosío Villegas y

${ }^{23}$ Luis Medina, Civilismo..., p. 91.

\begin{abstract}
criticas de don Daniel Cosio Villegas $y$
\end{abstract}
Jesús Silva Herzog, quienes no dejan de alertar sobre la creciente deshonestidad y la entronización del peculado en los asuntos públicos, aunque sin resultados pues la corrupción sirvió para la acumulación de capital a la emergente burguesía surgida durante la guerra, formada tanto por nacionales como por extranjeros llegados al país en busca de estabilidad y paz, y por los mismos funcionarios gubernamentales que lucraban con los contratos de obras públicas.

Cuando Miguel Alemán asume la presidencia -con el forzado beneplácito del poderoso vecino, cuyo candidato era el brillante canciller avilacamachista, Ezequiel Padilla-, se barrunta la guerra fría; se evaporan las divisas acumuladas durante la guerra, pues el deterioro en términos de intercambio y la fiebre de importaciones, necesarias o no, han agotado las reservas; no llegan en las cantidades acostumbradas los dólares enviados al país por los braceros, porque el trabajo de éstos ya no es tan necesario para la economía estadunidense que surge de la guerra; emprenden el vuelo los capitales golondrinos que habían llegado en calidad de refugiados, y la industria mexicana tiene que hacer frente a la creciente competencia de la estadunidense, que vuelve por sus fueros.

La ayuda de Estados Unidos era necesaria para llevar adelante los ambiciosos planes económicos del nuevo régimen, aunque siempre se insistió en que el desarrollo debía lograrse con recursos propios y bajo la conducción de mexicanos. Se requería modernizar el envejecido parque industrial que había trabajado al máximo de su capacidad durante la contienda; sacar a Pemex de su postración para que efectivamente fuera el pivote dela independencia económica, y lograr el aval para préstamos intergubernamentales en los nuevos organis-
7

3 


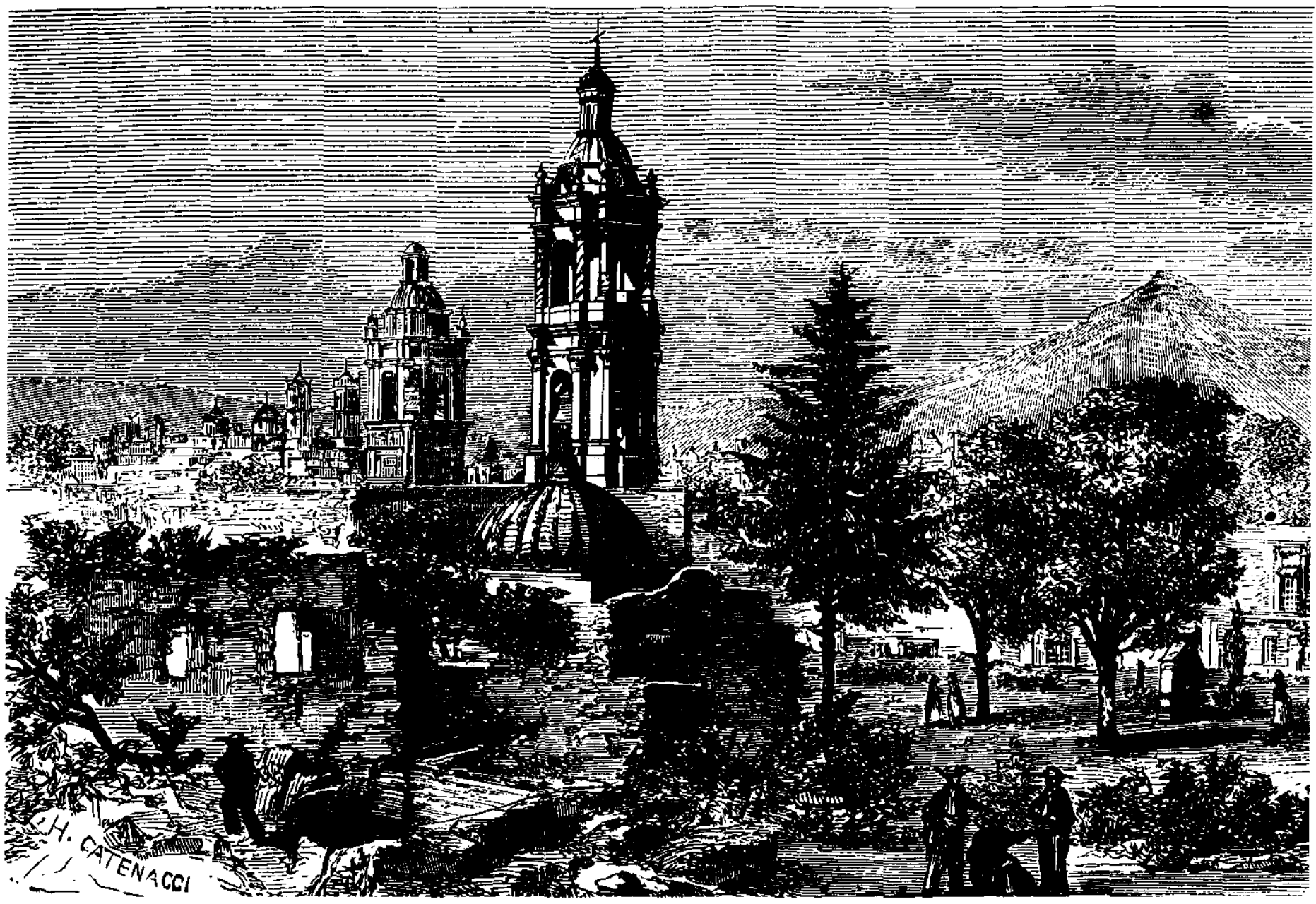

mos multilaterales, como el Eximbank y el Banco Internacional de Reconstrucción y Fomento (BIRF), para construir la proyectada infraestructura. En resumen, al término de la segunda guerra, México necesitaba el beneplácito y la complacencia de Estados Unidos ante su esfuerzo industrializador pues se trataba del principal cliente, con un porcentaje que oscilaba entre 70 y $80 \%$, de nuestro comercio exterior. A cambio del alistamiento mexicano en la guerra fría, Estados Unidos aceptaba el sistema político nacional, el cual mostraba cada vez más su eficacia en términos de contención social, así como de la peculiar estructura económica promulgada en la Constitución de 1917.

El comunismo no desveló a los gobernantes mexicanos. La retórica dela guerra fría le vino de perlas al régimen alemanista porque le permitió desembarazarse de la incómoda compañía de los izquierdistas instalados en el gobierno y en las centrales obreras. Se dejaron atrás las cuidadosas contemporizaciones con estos camaradas de la revolución, que fueron necesarias en su momento, pero ya no más, cuando se emprendía la construcción de un México moderno que se quería libre de estériles pugnas ideológicas.

Por lo demás, como señalaba en una entrevista el presidente Alemán, durante su régimen "se combatirá al comunismo en el país con hechos, no con palabras". ${ }^{24}$ El 12 de junio de 1951, en entrevista con la misma reportera Betty Ross, expuso lo que entendía por fundamento de la democracia: "Para mí, la base de la democracia es contar con un pueblo que tenga buena habitación, que coma bien y que se vista bien. Esto le da fuerza para

${ }^{24}$ Excélsior, 22 de marzo de 1949. 

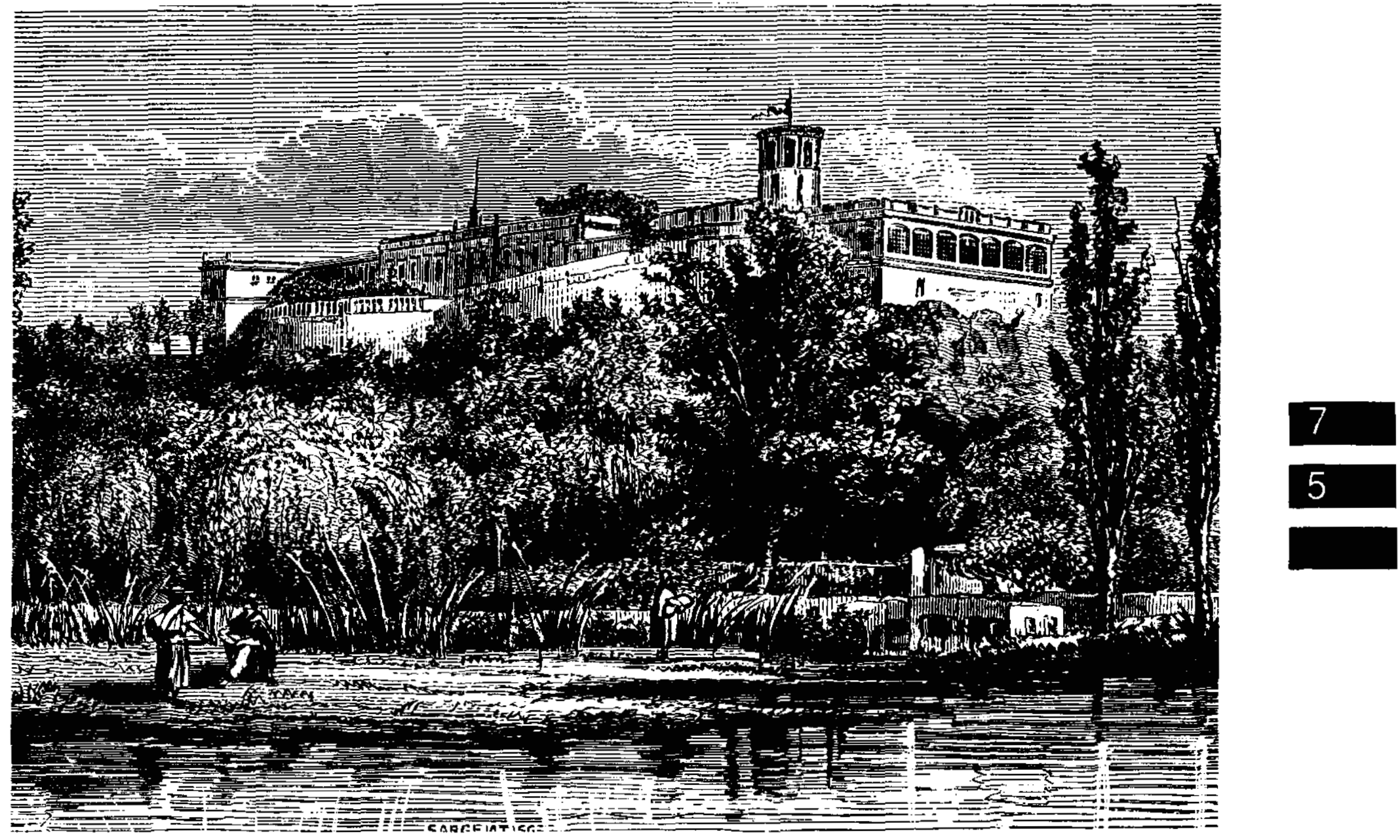

no aceptar ninguna filosofía exótica." Agregó que su ideal era "hacer de México una nación que viva bien... Todos mis esfuerzos se encaminan a ese fin" ${ }^{25}$ Ante tal prosperidad, el comunismo no tendría un caldo de cultivo adecuado.

Durante su gobierno se reafirmaron los principios de la buena vecindad con Estados Unidos -que salieron fortalecidos de la contienda con una planta industrial que representaba $50 \%$ en términos mundiales-y se abrigó la esperanza de que el triunfo de las democracias se resolvería enun mayor apoyo a los países atrasados, que querían contar también con las ventajas de una vida democrática solamente posible en condiciones de solidez económica y paz social. Estas esperanzas de que, por fin, occidente dirigiría su atención hacia los países dela

\footnotetext{
${ }^{25}$ Excélsior, 12 de junio de 1951.
}

periferia capitalista fueron desinfladas por el Plan Marshall, que se volcó hacia la recuperación de Europa, y por la doctrina Truman, que alertó sobre el avance comunista en las fronteras de la Unión Soviética y sobre la división del mundo en dos bandos irreconciliables, lo que obligó a destinar cuantiosos recursos a contenerla "mancha roja". Para colmo, la Carta de La Habana amenazó con imponer el libre cambio a nivel mundial, lo que favorecería a los países desarrollados en perjuicio de los esfuerzos de los débiles por superar su situación.

Junto a lo anterior, hay que contar al Tratado Interamericano de Asistencia Recíproca (TIAR), primero de los pactos militares de la guerra fría, el cual dio a entender en forma descarnada que los afanes de superación económica de los países latinoamericanos le importaban un comino al líder del mundo libre; su principal preocupación consistía en reac- 
cionar ante las amenazas a su seguridad nacional por parte del expansionismo soviético y no en procurar el bienestar de su patio trasero. De ahí su insistencia en la necesidad de la defensa continental y el rearme de nuestros ejércitos con material de desecho de la guerra; con esto se liberaba de chatarra e inoculaba, de paso, la doctrina anticomunista.

\section{EL PROGRAMA DESARROLLISTA}

El programa de gobierno propuesto al país por el nuevo equipo gobernante está comprendido en la siguiente cita extraída del discurso de toma de posesión del licenciado Alemán. Se procurará:

El enriquecimiento del paîs, la lucha contra la pobreza y la abolición de la miseria; el impulso de la salubridad nacional, la elevación del saber y la cultura en todos sus grados; el mantenimiento de las reformas sociales en favor de la clase laborante, las garantías al esfuerzo de toda empresa progresista, el fortalecimiento de las libertades humanas y los derechos políticos y una administración de justicia expedita y honrada. ${ }^{26}$

El discurso toral del régimen alemanista parte de los siguientes supuestos: México no es rico, es decir, no es la cornucopia que se configura físicamente en la forma de nuestro territorio y que nos ha encandilado desde los tiempos del barón de Humboldt. El país carece de agua; sólo $2 \%$ de sus tierras es susceptible de cultivo sin riego; su agricultura es de temporal, lo que hace depender las cosechas de la buena voluntad del dios

${ }^{26}$ XIVI Legislatura, Los presidentes de México, 1966 , t. Iv, p. 358.
Tláloc; más de la mitad del territorio nacional es semidesértico por lo que, para hacer eficiente nuestra agricultura, necesitamos, además de seguridad en la tenencia de la tierra -sentida demanda que viene desde tiempo atrás y que es bandera política del PAN-, una cuantiosa inversión en sistemas de riego para ampliar la frontera agrícola y aprovechar tierras ociosas, junto a la tecnificación y mecanización de la agricultura, tareas indispensables si se desea elevar la productividad. En el programa de gobierno se asentaba que se irrigaría un millón de hectáreas, con un costo de 1500 millones de pesos. El hincapié hecho por el gobierno en la necesidad de aumentar la productividad agrícola lo llevó a apoyar la agricultura privada, ya que los ejidos cargaban con el estigma de no producir lo suficiente. Casi en su totalidad, las nuevas tierras abiertas al cultivo fueron entregadas a particulares con lo que se ahondó la dicotomía en el campo mexicano: por un lado una agricultura tecnificada, capitalizada, dedicada sobre todo a cultivos de exportación y, por otro, la agricultura tradicional de minifundio, productora de los cultivos de subsistencia. En el mismo mes de diciembre de 1946, cuando tomó posesión, Alemán envió al Congreso una reforma al artículo 27 que otorgaba el amparo agrario y aumentaba la dotación de la pequeña propiedad, con lo que se cumplía con una de las finalidades del naciente régimen: otorgar seguridad al capital privado en el campo. Huelga decir que la CNC no protestó.

La política económica se basó, junto con el apoyo a la agricultura, en el impulso a la industrialización. Sin esta última, se afirmaba, seguiríamos siendo un paíssemicolonial, exportador de materias primas e importador de bienes manufacturados, encerrado en un círculo vicioso 
por el deterioro de los términos de intercambio y porque la dinámica de la economía venía del exterior.

Se insistía en que el énfasis puesto en la industrialización era una demanda nacional. Si bien resultaba cierto que México era un país políticamente soberano, le faltaba todavía alcanzar la independencia económica considerada no en el sentido de autarquía, imposible de lograr por lo demás en el mundo de la posguerra y que tuvo ejemplos nefastos en la Alemania e Italia fascistas, sino en el de que el país se bastara a sí mismo en lo esencial, sobre todo en materia de alimentación popular, para no quedar a merced de la buena voluntad delos países poderosos. Sin la independencia económica, las demás libertades carecían de sentido y sustento. Como expresó el presidente en febrero de 1951, ante la dirigencia del PRI:

No hay conquista social segura si no se tiene una base económica en qué apoyarse. Por ello, todos los mexicanos debemos trabajar sin descanso. Los problemas que afrontamos son grandes; pero el final será satisfactorio. Hay que tener fe inextinguible en la grandeza de México. ${ }^{27}$

\footnotetext{
En cuanto a la industrialización, el candidato presidencial del partido oficial externó lo siguiente en septiembre de 1945, en Acapulco, Guerrero, cita que da una idea muy clara de lo que pretendía a este respecto:

Industrializando nuestras materias primas agrícolas podremos aumentar considerablemente los ingresos tan escasos que hasta hoy reciben, por la venta de sus productos, los ejidatarios y pequeños propietarios. Industrializando nuestras ma-

${ }^{27}$ Presidencia de la República, Miguel Alemán, 1952, p. 288.

terias primas minerales podremos asentar la industria extractiva sobre bases más sólidas y estables, en vez de que continúe dependiendo casi enteramente de las fluctuaciones del mercado externo. La industrialización irá exigiendo un número cada vez mayor de obreros, a los que podrán pagarse salarios cada vez más elevados. Y el incremento de la renta percibida por los trabajadores del campo y de la ciudad ampliará en forma progresiva la capacidad de consumo y el mercado interno de nuestra industria. ${ }^{28}$

Se deseaba que los frutos de la industrialización llegaran a todos los mexicanos; si no, se frustraría el aumento del mercado interno, condición principal de aquélla. En el discurso que pronunció para aceptar que la CTM lo postulara como candidato presidencial, Alemán señaló que la revolución industrial tenía siglo y medio de existencia, lo que hacía factible aprovechar esta experiencia histórica en nuestro favor, logrando una industrialización sin grandes costos sociales. Por ello aclaraba: " $\mathrm{La}$ industrialización de México debe tener como propósito inmediato la prosperidad nacional basada en que la compartan equitativamente todas las clases sociales." 29

Si la industrialización debería hacer llegar sus beneficios a todos los sectores de la población, se encarecía la necesidad de queel sentido de responsabilidad y de trabajo presidiera los afanes de trabajadores y patrones. Las conquistas obreras estaban promulgadas en la Cons-

${ }^{28}$ Conferencias de mesas redondas presididas durante su campaña electoral por el licenciado Miguel Alemán, 27 de agosto de 1945-17 de junio de 1946, 1949, p. 64.

${ }^{29}$ PRI, El pensamiento de la revolución mexicana, 1963, p. 162.

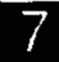

7

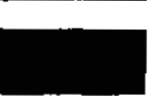


titución y eran irreversibles, por lo cual se trataba no tanto de ampliarlas, sino de consolidarlas y de hacer que llegaran al mayor número de trabajadores. Alemán declaraba en Veracruz, en ocasión de su gira electoral:

Los principios de la revolución mexicana son nuestros principios. Nuestro programa aspira a realizar la etapa del desenvolvimiento económico del país dictado por la revolución. Las conquistas agrarias y los derechos sindicales son realidades respetables que aseguran al proletariado nacional su participación en el bienestar que aquel desarrollo económico ha de traer para todos los sectores sociales de la comunidad mexicana. ${ }^{30}$

Junto con el énfasis puesto en el desarrollo agrícola y en el industrial que se p. 101 querían armónicamente integrados sin detrimento de ninguno de los dos, pues la industria no podía prosperar sin las materias primas y las subsistencias proporcionadas por la agricultura y la mano de obra proveniente del campo que, a su vez, consumiría los productos industriales, se hizo hincapié en la necesidad de cambiar la mentalidad del mexicano, considerada atávica; se desencadenó una lucha contra el conformismo, la apatía, el "Dios dirá", el eterno "mañana" de los pueblos débiles y desesperanzados. La norma debía ser una mentalidad dinámica, que buscara su mejoramiento material y moral, que vislumbrara el futuro con esperanzas de cambio. Adscrita a lo anterior estaba la convicción de que los remedios para nuestros males no provendrían del cielo, ni de un milagro de la Virgen morena, sino del esfuerzo y del trabajo de todos. La doctrina de la mexicanidad, que ensalzaba los valores

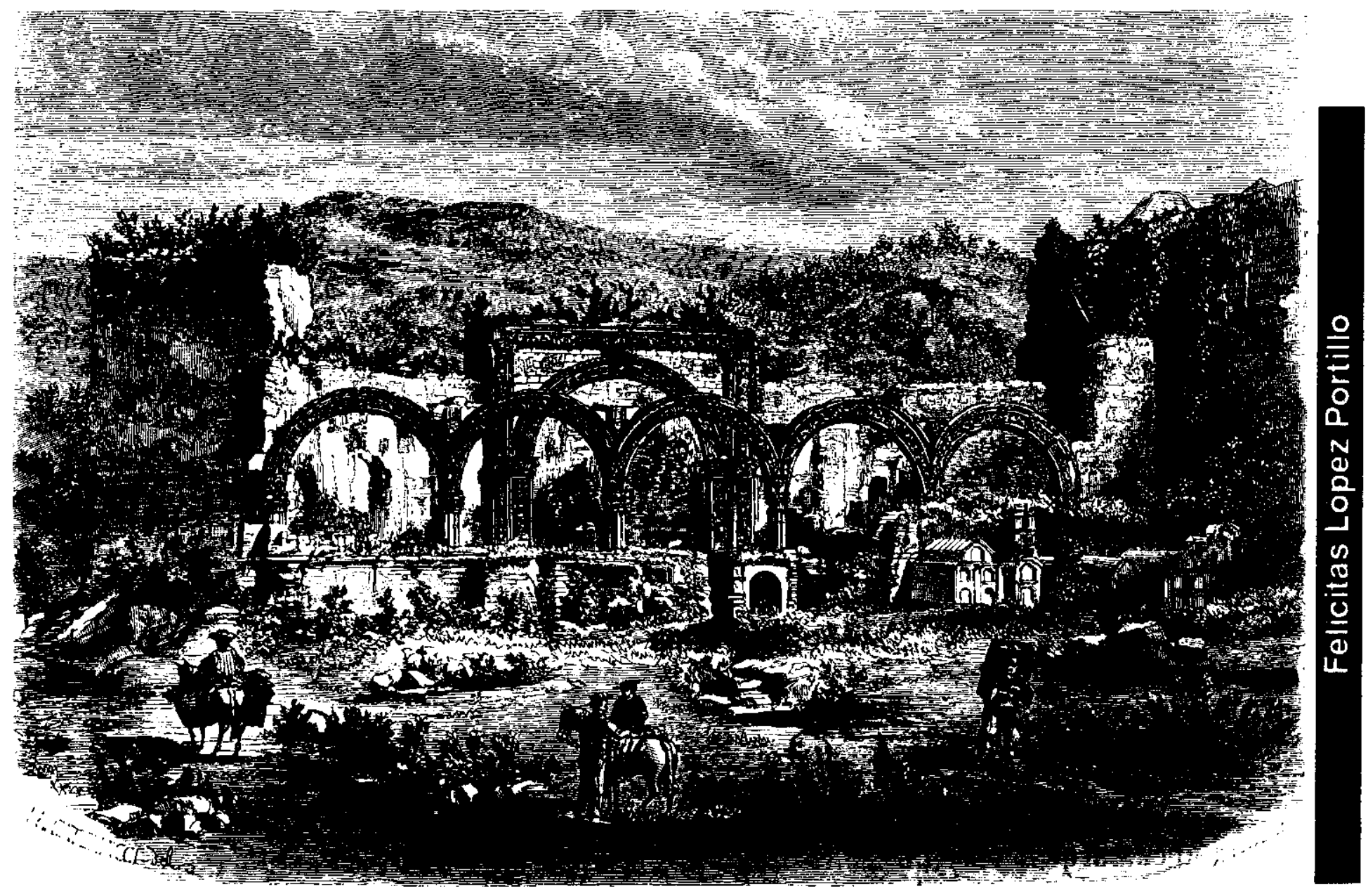


propios del mexicano a la vez que rechazaba el castrante complejo de inferioridad que a muchos embargaba, tenía como premisa la de que, echando mano de nuestras tradiciones y con el apoyo de nuestra peculiar idiosincrasia, los mexicanos podíamos salir adelante, pero sin olvidar que sin el trabajo fecundo y creador nada se lograría. Confianza en nosotros mismos, en nuestras fuerzas, en nuestra historia, en el legado de la revolución, que se remontaba a su vez al grito de Dolores de 1810, a la guerra de Reforma y de Intervención, luchas libertarias que desembocaban en la revolución de 1910, como lo había postulado Lombardo Toledano.

A mediados de la década de los 70 , Miguel Alemán asistió a la Universidad de Texas en Austin, para participar en un seminario sobre el sistema político mexicano, e indicó ahí lo que bien puede ser su testamento: "Nosotros creamos en México la conciencia de un mexicano responsable de su progreso. No debemos pensar en depender solamente del exterior; tenemos que hacer los mayores esfuerzos por nosotros mismos, superar las condiciones adversas y crear un país próspero, un gran país." ${ }^{11}$

El equipo de gobierno alemanista daba una importancia decisiva a su labor. Sus miembros se creían los fundadores de un México nuevo, dinámico, progresista. Anotaban la importancia de las obras públicas emprendidas, que darían sus mejores frutos en el futuro. En el primer informe de gobierno presentado por el ejecutivo, se lee:

Esta etapa es decisiva en el porvenir de nuestro país. Su fortalecimiento económi-

${ }^{31}$ Miguel Alemán contesta. Encuesta política, 1975, pp. 52-53. co nos dará base para lograr la felicidad de nuestro pueblo y nos llevará a realizar no solamente lo fundamental -producción agrícola y desarrollo industrial- sino también, y a su tiempo, mejores comunicaciones, escuelas, hospitales, nutrición, vestido $y$ habitaciones para nuestro pueblo. ${ }^{32}$

Se hacía hincapié en que al crecimiento económico debía acompañarlo el desarrollo integral del ser humano y en que, por ello, era necesario mejorary extender la educación a todo el pueblo. Un desarrollo económico que no se acompañara de un progreso intelectual y moral sería inútil, infructuoso, estéril. La educación contaba con un papel principalísimo en la dotación de un sentido humanista y ético al desarrollo material, aunque durante el sexenio nunca se proporcionó a este rubro más del $9 \%$ del presupuesto. ${ }^{33} \mathrm{Al}$ mismo tiempo que se manifestaba la necesidad de lograr un desarrollo armónico de la personalidad humana, se denunciaba que el nivel económico de México no estaba a la altura del desarrollo político y social alcanzado por los regímenes de la revolución, por lo que era necesario cumplir la tarea histórica de emparejarlos. Como expresó el candidato presidencial del PRI cuando compendiaba el programa de gobierno que se proponía realizar:

Durante esta campaña electoral hemos recorrido la mayor parte de nuestro país. Este contacto íntimo con nuestro territorio y con nuestro pueblo nos ha revelado que son muchas las necesidades de todo orden que la población mexicana padece; que p. 91.

${ }^{32}$ Primer informe del presidente Alemán, 1951,

33 James R. Wilkie, La revolución mexicana (1910-1976) 1978, p. 196.
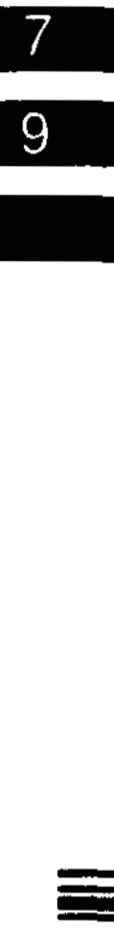
nuestrodesarrollo económico dista mucho de estar a la altura de nuestro desenvolvimiento social y político; que se precisa iniciar sobre bases firmes el incremento técnico de nuestra agricultura y realizar con decisión la industrialización del país, elevando el modo de vida y el nivel cultural del pueblo; y ése es, en esencia, nuestro programa. ${ }^{34}$

En los discursos y manifestaciones del régimen se ponderaba el respeto a los derechos humanos y a la democracia-se otorgó el voto a las mujeres en las elecciones municipales-, mas sin contenidos específicos. Es decir, se proclamaba que en México se vivía dentro de un estado de derecho y que las garantías de todos los ciudadanos estaban aseguradas, sin importar condición o clase social, lo que es por lo menos utópico en un país con las desigualdades del nuestro. No dejó de hostigarse a los sindicatos y líderes no incondicionales al gobierno, así como a la prensa, y se usó el artículo 145, el llamado de "disolución social", aprobado en octubre de 1941 con motivo de la guerra y bajo el pretexto de razones de seguridad nacional, en contra de individuos, sobre todo de izquierda, que no comulgaban con el régimen. Con todo, no puede decirse que en México se haya vivido bajo regímenes totalitarios, aunque no deje de aplicarse todo el rigor de la ley, y aun de otros recursos ajenos a ésta, cuando el gobiernosesiente amenazado en su coto político o en su monopolio de lo que considera "identidad eidiosincrasia nacionales". En el informe del primero de septiembre de 1948, el titular del ejecutivo anunció a sinarquistas e izquierdistas que no se permitirian interferencias en la marcha inconmovible de la revolución:

${ }^{34}$ Alemán, Discursos..., p. $12 \Upsilon$.
El respeto a las libertades ciudadanas es el mejor patrimonio de la revolución. Algunos irresponsables han creído que cuando el gobiemo presencia sin intervenir las extralimitaciones de esas libertades, acusa debilidad en su función dirigente. Mas esto no lo imposibilita para que, si las circunstancias lo requirieran, por bien de México, sea aplicado el mayor rigor de la ley para salvaguardar los intereses nacionales. ${ }^{35}$

\section{ESTADO Y REALIZACIONES MATERIALES}

En la Constitución de 1917, se promulgó que el Estado debe intervenir decididamente para paliar las desigualdades inherentes al sistema capitalista, abandonándose la pasividad del Estado liberal clásico que, dicho sea de paso, en ningún momento ha existido como tal en nuestro país. Por ello, la consigna del Estado surgido de la revolución ha sido el desarrollo capitalista, pero con la intención de acabar con las desigualdades sociales que se venían arrastrando desde la colonia. Si bien su contenido de clase es explícito, el Estado emanado de la revolución tiene que equilibrar las demandas populares recogidas en la Constitución, que son compromisos históricos derivados del triunfo del constitucionalismo sobre las otras facciones, con el impulso y la consolidación del capitalismo, que, por definición, al menos en nuestros países, prohija y acentúa la desigualdad social.

Por lo tanto, el Estado proporcionará las condiciones materiales y legales para el florecimiento de la iniciativa privada, pero ésta, a su vez, debe satisfacer los requerimientos de la mano de obra

${ }^{35}$ XIVI Legislatura, Los presidentes, 1966, t. IV, pp. 401-402. 
asalariada -que por lo demás, está controlada por el Estado a través del pacto corporativo-y dedicarse a la creación de riqueza, mientras el monopolio político corresponde a la "familia revolucionaria". De ahí el impulso a la infraestructura -comunicaciones, obras de riego, puertos, desarrollo integral de importantes cuencas fluviales-, junto al de las industrias básicas a cargo del Estado, que proporcionan los insumos necesarios para la industria a precios subsidiados -petróleo, electricidad, acero. En el programa de gobierno alemanista se especificó claramente la función del aparato estatal:

El Estado debe brindar la más amplia libertad para las inversiones particulares, reconociendo que el desarrollo económico general es campo primordialmente de la iniciativa privada. Aquellas empresas indispensables para la economía nacional a las que no atienda la iniciativa particular, serán fomentadas por el Estado, quien hará las inversiones necesarias y crearálos órganos requeridos para su funcionamiento y desarrollo. ${ }^{36}$

Se buscaban criterios de eficiencia económica, lo que no dejó de señalarse sobre todo en el caso de los ferrocarriles - la administración de los cuales había sido entregada a los trabajadores por don Lázaro, aunque posteriormente éste diera marcha atrás- y de Petróleos Mexicanos, empresas que eran vistas como zonas de desastre. En su discurso de toma de posesión, Alemán dijo que

sin transportes y sin combustibles son imposibles el incremento de la producción agrícola y la industrialización. La industria petrolera y los ferrocarriles son patrimo- nio de la nación. La eficiencia de esas

${ }^{36}$ Alemán, Programa..., p. 17. empresas es, en consecuencia, de interés público. Su manejo debe estar sujeto a un criterio más comercial que político. ${ }^{37}$

Prueba de su actitud al respecto, fuela reacción gubernamental ante el paro petrolero ocurrido en diciembre de 1946 que fue sofocado sin miramientos por el ejército.

La labor constructiva del régimen, ejemplificada en la sentencia alemanista de "estamos haciendo patria" que se expresaba en cada inauguración de escuelas, mercados, presas, hospitales, aeropuertos, etc., se demuestra en la efectiva modernización de la infraestructura del país, sobre todo en el ramo de comunicaciones. Se concluyó la carretera panamericana Cristóbal Colón, que une Ciudad Juárez con Ciudad Cuauhtémoc, en Chiapas; igualmente el ferrocarril del sureste, que une Coatzacoalcos con Campeche, y el Sonora-California; se inició la construcción del Durango-Mazatlán y empezó a colocarse vía ancha en los antiguos rieles heredados del porfiriato. Se inauguró la autopista México-Cuernavaca. Se modernizaron los sistemas telegráfico y telefónico. Se implantó un programa de desarrollo integral de las cuencas fluviales más importantes del país, como la del Papaloapan en el Golfo de México, la del Tepalcatepec en el Pacífico, la del Grijalva en el sureste y, en el noroeste, se crearon los distritos de riego del río Fuerte en Sinaloa y del Yaqui y Mayo en Sonora, al igual que el del río Colorado, en Mexicali, Baja California. Setenía el propósito, con estos planes, de emular lo hecho en el valle del Tennessee en tiempos del New Deal de Franklin D. Roosevelt. Aclaremos que muchas obras, sobre todo del ramo de comunicaciones, venían de tiempo

37 PRI, El pensamiento..., pp. 190-191 
atrás y sólo se concluyeron durante este sexenio.

En marzo de 1949, cuando Miguel Alemán visitó la cuenca del Tepalcatepec -la comisión de desarrollo integral de la misma se hallaba presidida por el general Cárdenas-, declaró:

No puedo menos de insistir ante el país en que México necesita desarrollar una sólida potencialidad económica. Sin ella no haremos nada y no será posible desarrollar una obra de beneficio popular. Por eso tratamos de aumentar la producción agrícola y de incrementar las zonas industriales de toda la república. ${ }^{38}$

Se inauguró la era de los multifamiliares con la unidad Miguel Alemán, sobre la avenida Félix Cuevas, que consta de nueve edificios de 13 pisos cada uno, destinada a los burócratas. Se construyeron varias colonias nuevas en la ciudad de México, con un desenfrenado ánimo urbanista que desde entonces alarmaba a más de uno. Ante las críticas de que debía actuarse con más detenimiento en la ingente labor constructiva, a la que se acusaba de propiciar inflación y de erigir obras públicas dispendiosas, respondia Alemán: "Se nos acusa de que obramos a la ligera; pero a todo ello respondemos con hechos consumados y con obras que responden a un ansia colectiva y a una necesidad de recuperación económica." 39

A la par de la constructiva labor material se crearon comisiones para el mejoramiento del maíz, de la investigación científica, del café y del turismo, entre otras; se aumentaron las instituciones de crédito: Comisión Nacional de Valores, Comisión Nacional de Seguros, Banco

${ }^{38}$ El Nacional, 27 de marzo de 1949.

${ }^{39}$ El Universal, 25 de enero de 1948.
Nacional Cinematográfico, Patronato del Ahorro Nacional, Monte de Piedad, Financiera Nacional Azucarera y Banco Nacional de Transportes. Se reforzaron las atribuciones de Nacional Financiera (NAFINSA), cuyos recursos se orientaron preferentemente hacia diversas industrias básicas como la generación de energía eléctrica y la elaboración de hierro y acero, pilares de la industrialización. Sus fondos provenían del gobiemo federal, de inversiones internas en valores de NAFINSA y de préstamos externos de organismos como el Eximbank y el BIRF.

El mayor logro en términos culturales del régimen fue la construcción de Ciudad Universitaria, digno aposento para el "futuro dela patria". Se construyó igualmente la ciudad politécnica y numerosos tecnológicos, ya que se privilegiô la enseñanza técnica que proporcionaría el personal calificado que demandaba la industria. La educación superior gozó de una atención especial, mientras se descuidaba la elemental.

Se crearon el Instituto Nacional de Bellas Artes, el Nacional Indigenista, el Nacional de la Juventud Mexicana, la Casa de México en París, y se realizó la primera exposición de arte mexicano en Europa a cargo de Fernando Gamboa. Se descubrieron los supuestos restos de los niños héroes en Chapultepec y se inauguró el monumento respectivo, mientras doña Eulalia Guzmán aseguraba que los restos encontrados en Ixcateopan, Guerrero, pertenecían al "joven abuelo" Cuauhtémoc, lo que armó una zarabanda con los hispanófilos, que no se quedaron atrás y desenterraron los de Hernán Cortés. Tuvo lugar el primer Congreso de Academias Nacionales de la Lengua Española en la ciudad de México, reunión que no contó con la asistencia de la España franquista. Se celebró con bombo y platillo el cuarto centena- 
rio de la Universidad Nacional, lo quefue aprovechado para homenajear al ilustre egresado del Alma Mater, el presidente de la república.

En cuanto al petróleo, se finiquitó el problema de las indemnizaciones de las compañías extranjeras y se construyeron las refinerías de Salamanca y Azcapotzalco, además de varios oleoductos, para unir las zonas productoras con las de consumo. Por primera vez se empleó industrialmente el gas natural asociado al petróleo y, bajo la batuta del eficaz Antonio J. Bermúdez, la industria petrolera se puso a flote y cumplió satisfactoriamente con su misión de proporcionar combustible barato y en forma eficiente a la industria. Como lo declaraba el mismo Bermúdez el 18 de marzo de 1952: "Un índice del desarrollo y progreso de $\mathrm{Pe}$ tróleos Mexicanos es el volumen de sus ingresos. En 1946 sumó 569965000 , y en 1951 fue de 1838594500 ."40

Recién iniciado el sexenio se presentó el problema de la fiebre aftosa, que amenazaba con diezmar a la población ganadera del país. Se optó por la vacunación en lugar del "rifle sanitario" que había provocado descontento en el campo. En 1951 se declaró acabada la epidemia que se aprovechó, hasta donde ello era posible, para sustituir la tracción animal por la mecánica.

Terminemos este recuento dela época alemanista con esta declaración mesiánica de su principal representante a un periodista, en 1950: "Mi régimen no podía dejar de realizar lo que ha realizado. Le correspondía, como una inevitable imposición histórica. Estamos en el momento culminante de nuestro progreso. O mejor aún: en el momento supremo de

${ }^{40}$ Presidencia de la República, Miguel Alemän..., p. 288. nuestro impulso, que ya no puede detenerse", ${ }^{41}$ optimismo que ya quisiéramos hoy, cuando asistimos a un nuevo rumbo de nuestro devenir histórico luego de agotarse el que tan dinámicamente inaugurara el alemanismo.

Mas veamos la base material en que se sustentaba la acción gubernamental. En primer lugar, señalemos que la población rural abarcaba $69 \%$ de la población total. Para 1952, apenas 31\% de la población era urbana, de un total de $27.8 \mathrm{mi}$ llones de personas. ${ }^{42} \mathrm{El}$ crecimiento del PIB tuvo un promedio anual de 5.7\% entre 1947 y 1952, tasa que, según la investigadora Blanca Torres (autora de uno de los pocos libros completos y confiables sobre el régimen), es ligeramente inferior a la del periodo avilacamachista, ${ }^{43}$ aunque de todos modos sea superior a la tasa de crecimiento demográfico. La división por sectores del PIB fue la siguiente: en 1946, el sector primario contribuía con el $17.5 \%$, porcentaje que se mantiene en 1952 , mientras el secundario pasa de $25.4 \%$ en el primer año citado a $27.5 \%$ en el segundo. Por su parte, el sector servicios pasó de $57.1 \%$ en 1946 a $55 \%$ en $1952 .{ }^{44}$ En cuanto a la población económicamente activa, ésta alcanzó en 19528.8 millones de personas, de los cuales la industria ocupaba $16 \%$, los servicios $26 \%$ y el sector primario 57.5 por ciento. ${ }^{45}$

La agricultura cargó con el peso de la industrialización, pues si bien es cierto que se hicieron grandes obras de riego

${ }^{41}$ Ibid., pp. 11-12.

${ }^{42}$ Blanca Torres, Hacia la utopia industrial, 1964, p. 52.

${ }^{43} \mathrm{Ibid}$., p. 48.

4 Porcentajes obtenidos del cuadro núm. 1 Producto interno bruto por actividades, 1946-1952, ibid., p. 52.

45 Ibid., p. 50.

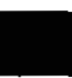


que ampliaron la frontera agrícola y se procuró modernizarla con maquinaria e insumos, los beneficios se dirigieron hacia los propietarios privados dedicadosa la exportación y a la producción de materias primas para la industria, y no hacia los productores de subsistencias que formaban la gran mayoría de la población rural. Pese a ello, hubo dinamismo en ese sector gracias a las anteriores medidas gubernamentales de reparto de tierras y de ampliación de la cobertura estatal. Durante el sexenio alemanista, las inversiones en irrigación absorbieron $17 \%$ de la inversión federal total, ${ }^{46}$ lo que manifiesta el interés del gobierno en estas tareas técnicas, a la par de una escasa atención hacia los ejidos aunque no dejaron de repartirse tierras, ritual imprescindible de los gobiernos posrevolucionarios.

El investigador estadunidense James W. Wilkie escribe acerca del interés primordial del gobierno: "Alemán proyectó un gasto medio en favor de la economía que llegaba casi a $40 \%$ del presupuesto; sin embargo, llegó a gastar en desarrollo económico hasta $51.9 \%$ del presupuesto extendido. ${ }^{\text {77 }}$ Este hincapié en el desarrollo económico tuvo su correlato en la disminución de los gastos sociales, que durante el alemanismo fueron recortados de 21 a 17\% del presupuesto. El mismo estudioso indica que en 1952 se utilizó para gastos sociales $11.2 \%$ del presupuesto, el más bajo desde $1927 .{ }^{48}$ Los personeros del gobierno insistían en que, con la mejoría de la situación económica, se superarían a su vez las condiciones educativas, sanitarias, cul-

${ }^{46}$ Roger D. Hansen, La politica del desarrollo, 1971, p. 110.

${ }^{17}$ Wilkie, La revolución..., p. 72.

${ }^{48}$ Ibid., p. 190. turales, etc. de la población. Se aducía que el crecimiento económico terminaría por derramar sus beneficios en todos los mexicanos. Como escribe Wilkie: "El gobierno mexicano ha preferido hacer resaltar las estadísticas del desarrollo económico, que son impresionantes, para dar a entender que el cambio social ha ido a la par de los adelantos materiales del país." ${ }^{49}$

Se aceptaba que el desarrollo económico acarreaba costos sociales, pero se confiaba en que éstos serían transitorios. Los precios siempre fueron adelante de los salarios que, para colmo, desde el periodo avilacamachista arrastraban una pérdida acumulada de $36 \%$ de su poder adquisitivo con respecto a los niveles de $1940 .{ }^{50} \mathrm{~A}$ pesar de lo anterior, la investigadora Torresseñala que la participación del capital en el ingreso durante el gobierno alemanista se redujo de $60.8 \%$ a $58.1 \%$, y la del trabajo y otros ingresos pasó de $39.2 \%$ a $41.9 \%,{ }^{51}$ lo que demuestra que hubo un ligero aumento de los ingresos reales promedio de los trabajadores asalariados. Según Roger D. Hansen, "este incremento en el ingreso real por trabajador, en un momento en que las tasas del salario real se reducían, refleja las modificaciones de la estructura ocupacional de México". ${ }^{52}$

Se prefirió financiar inflacionariamente los gastos del sector público antes que aplicar mayores impuestos, que se contaban entre los más bajos del mundo; ello porque se sostenía que con el aumento se nulificaban los demás incentivos a la iniciativa privada. Para que se vea la

${ }^{49}$ Ibid., p. 208.

so Jorge Basurto, Del avilacamachismo al alemanismo, 1984, p. 49.

${ }^{51}$ Torres, Hacia la utopía..., p. 54.

${ }^{52}$ Hansen, La política..., p. 100. 
continuidad de los regímenes emanados de la matriz revolucionaria, tenemos los siguientes datos: "Los gastos federales destinados al desarrollo económico, como una proporción del presupuesto total, se elevaron de $22 \%$ en $1933-34$, a un promedio de $52 \%$ en los doce años comprendidos entre 1947 y $1958 .{ }^{" 53}$ Hansen, autor de la cita precedente, anota que la envidiable estabilidad política del país hizo posible que cerca de $70 \%$ de la inversión interna mexicana, a partir de 1940 , haya sido generada por el sector privado, aunque no deja de resaltar el papel dinamizador de la inversión pública, a la que ve como altamente eficiente: ${ }^{54}$

En ningún momento-escribe-entre 1940 y 1960 , el sector público absorbió más de $13 \%$ del total del producto nacional bruto. Durante la mayor parte del periodo esa cifra fue menor de $11 \%$; sin embargo, el gobierno fue capaz de ahorrar aproximadamente $40 \%$ de ese ingreso, para destinarlo a inversiones públicas. ${ }^{55}$

Lo característico del periodo alemanista fueron las grandes utilidades logradas por los capitalistas -hecho que, por lo demás, no es una novedad en nuestro país-, que no siempre fueron derivadas hacia la inversión industrial o los bienes de capital como quería el gobierno, sino hacia la compra de bienes raíces, la realización de gastos suntuarios o la creación de empresas comerciales no productivas.

Se hizo frente exitosamente a las turbulencias económicas que no dejaron de darse con motivo de la recomposición mundial de la posguerra, y a la carestía e

53 Ibid., p. 91

${ }^{54}$ Ibid., p. 11.

55 Ibid., p. 66. inflación que se arrastraban desde sexenios anteriores. Sobrevino una devaluación de casi $100 \%$ y, por medio de la Compañía Exportadora de Maíz, S.A. (CEIMSA), se reguló el comercio de productos básicos para controlar la especulación.

Se achaca al alemanismo la llegada masiva de capital extranjero, lo cual no es cierto, ya que el ahorro interno fue la principal fuente de financiamiento de la inversión. Es verdad que aceptó la necesidad del capital extranjero, pero con la condición de que se invirtiera en áreas necesarias, que no entrara en competencia con el capital nacional, que trajera tecnología y que no descapitalizara al país. A pesar de que se hicieron serios esfuerzos por contratar préstamos externos, sobre todo intergubernamentales o de los nuevos organismos multilaterales nacidos en Bretton Woods, préstamos que se consideraban más ventajosos, los resultados no fueron muy satisfactorios, pues apenas llegaron unos 120 millones de dólares del Eximbank y del BIRF, ${ }^{56}$ la mayor parte de los cuales se destinó a dependencias gubernamentales y empresas paraestatales, aunque también a proyectos privados. Porsu parte, la deuda externa a fines de 1952 alcanzaba la cantidad de 319 millones de dólares, con todo y reclamaciones petroleras y agrarias. $^{57}$

A contrapelo de la retórica revolucionaria de nuestra clase política y de los esfuerzos en pos de un desarrollo que se quería armónico e integrado, en México la desigualdad sigue siendo la mayor afrenta histórica de nuestra sociedad. Como lo señala contundentemente Hansen, "el grado de desigualdad existente en la distribución mexicana del

\footnotetext{
${ }^{56}$ Torres, Hacia la utopía..., p. 183.

s7 Ibid., p. 184.
}

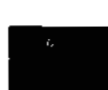


ingreso, como quiera que se mida, excede la que impera en la mayoría de los países en desarrollo del mundo" ${ }^{58}$ lo que no deja de ser un saldo desalentador -por decir lo menos-de la primera revolución social de este siglo.

\section{BIBLIOGRAFIA}

-Alemán, Miguel, Programa de gobiemo, México, s.e., 1945. México, 1946.

-Basurto, Jorge, Del avilacamachismo al alemanismo (1940-1952), SigloXXI Editores/ Instituto de Investigaciones Sociales, UNAM, México, 1984 (La clase obrera en la historia de México, 11).

- Beteta, Ramón, Entrevistas y pláticas, Editorial Renovación, México, 1961.

-Confederación de Trabajadoresde México, PorlagrandezadeMéxico conMiguelAlemán, Impresora S. Turanzos del Valle, México, 1945.

- Conferencias de mesas redondas presididas durante su campaña electoral por el licenciado Miguel Alemán, 27 de agosto de 1945-17 de junio de 1946, introducción y síntesis de Manuel Germán Parra, Talleres Gráficos de la Nación, México, 1949.

-Hansen, Roger D., La política del desarrollo mexicano, Siglo XXI Editores, México, 1971.

${ }^{58}$ Hansen, La política..., p. 113.
-Lombardo Toledano, Vicente, Selección de obras de Vicente Lombardo Toledano, Ediciones del Partido Popular Socialista, México, 1972.

-Medina, Luis, Del cardenismo al avilacamachismo, El Colegio de México, México, 1978(Historia dela revolución mexicana, 18).

-, Civilismo y modernización del autoritarismo, El Colegio de México, México, 1982(Historia de la revolución mexicana, 20).

-XIVI Legislatura, Lospresidentes de México ante la nación. 1821-1966, Cámara de Diputados, México, 1966.

-Miguel Alemán contesta. Encuesta politica, University of Texas, Austin, 1975.

-Paoli Bolio, Francisco José, Estado y sociedad en México. 1917-1984, Editorial Océano, México, 1985.

-Partido Revolucionario Institucional, $E l$ pensamiento de la revolución mexicana a través de sus estadistas, 1903-1963. Antologias, Talleres Gráficos de la Nación, México, 1963.

-Presidencia de la República, Miguel Alemán. Biografia de su obra, 1946-1952, Oficina de Prensa de la Presidencia de la República, México, 1952.

-Primerinforme del presidente Alemán. 1 de septiembre de 1947, Editorial Ruta, México, 1951.

-Torres, Blanca, Hacia la utopia industrial, El Colegio de México, México, 1964 (Historia de la Revolución Mexicana, 21).

-Wilkie, James R., La revolución mexicana (1910-1976). Gasto federal y cambio social, Fondo de Cultura Económica, México, 1978. 